\title{
Association of EGFR and KRAS mutations with expression of p-AKT, DR5 and DcR1 in non-small cell lung cancer
}

\author{
X. D. ZHAO ${ }^{1}$, H. B. $\mathrm{DENG}^{2}$, C. L. $\mathrm{LU}^{3}$, Y. X. BAO ${ }^{4}$, X. $\mathrm{LU}^{2}$, L. L. DENG ${ }^{5, *}$ \\ ${ }^{1}$ Department of Laboratory, The Second Affiliated Hospital of Harbin Medical University, ${ }^{2}$ Dental Hospital, The First Affiliated Hospital of Harbin \\ Medical University, ${ }^{3}$ Department of Biopharmaceutical Sciences, College of Pharmacy, Harbin Medical University, ${ }^{4}$ Department of Respiratory \\ Medicine, The Second Affiliated Hospital of Harbin Medical University, ${ }^{5}$ Department of Oncology, The Second Affiliated Hospital of Harbin \\ Medical University, Harbin, Heilongjiang, People's Republic of China
}

*Correspondence: dengdoctor@126.com

Received June 5, 2016 / Accepted October 3, 2016

\begin{abstract}
The activation of AKT is one of the causes of resistance to epidermal growth factor receptor (EGFR)- tyrosine kinase inhibitors (TKIs). Tumor necrosis factor-related apoptosis-inducing ligand (TRAIL) combines with related receptors to trigger apoptosis or protect the cells against TRAIL apoptosis. This research focused on the association of EGFR and KRAS mutations with expression of AKT, p-AKT, DR5 and DcR1 in non-small cell lung cancer. 82 NSCLC patients were included in the study. xTAG liquichip techonolgy (xTAG-LCT) was applied to investigate the genetic mutation of EGFR and KRAS, Quantitative Real-time PCR was used to test the mRNA expression of AKT, DR5 and DcR1 and Western Blot was applied to test the protein expression of AKT, p-AKT, DR5, and DcR1. We found that of 82 patients, 31 cases had EGFR-activating mutations, more common in female, adenocarcinoma, and non-smoker patients; 9 cases had KRAS mutations, frequently found in patients with smoking history. The expression of AKT and p-AKT correlated with staging, tumor differentiation, and lymph node metastasis. The expression of DR5 in phase III and low differentiation tumor was significantly higher than that in phase I+II and high and median differentiation tumor; the expression of DcR1 in phase III and low differentiation tumor was significantly lower than that in phase I+II and high and median differentiation tumor. Compared with EGFR and KRAS wild type, in NSCLC tissue with EGFR and KRAS mutations, the expression of AKT and p-AKT was significantly higher. These results suggest that EGFR and KRAS mutation status was associated with the expression of AKT and p-AKT. AKT, p-AKT, DR5, and DcR1 all took part in the occurrence and development of NSCLC, and may become a reference index to evaluate the prognosis of NSCLC.
\end{abstract}

Key words: epidermal growth factor, KRAS, p-AKT, receptor, carcinoma, non-small-cell lung

So far non-small cell lung cancer (NSCLC) is the leading cause of cancer-related death worldwide. An important therapeutic strategy of advanced NSCLC is the multidisciplinary synthetic therapy including traditional chemotherapy and targeted drug therapy. Epidermal growth factor receptor (EGFR) tyrosine kinase inhibitors (TKIs) have shown significant therapeutic effect in NSCLC with EGFR mutations [1]. But the drug resistance of EGFR TKIs remains one of the difficulties to be solved urgently in clinical practice. EGFR is a transmembrane receptor with tyrosine kinase activity encoded by oncogene erbB. Under the stimulation of ligands such as epidermal growth factor (EGF) and transforming growth factor- $\alpha$ (TGF- $\alpha$ ), the receptor is autophosphorylated, leading to the activation of three downstream signal transduction pathways, PI3K/AKT, RAS/RAF-MAPK, and STAT3, which transduct signal into cells, so that regulate cell proliferation, anti-apoptosis, and angiogenesis, and promote the formation and development of tumor [2, 3]. Preliminary studies have indicated that the activation of PI3K/AKT/mTOR signaling pathway is one of the causes of resistance to EGFR-TKIs, but the specific mechanism is not clear [4], may be related to the higher activation of mutant EGFR than wild type EGFR, which further induces the higher activation of AKT and STAT [5]. Through phosphorylation of a series of downstream signaling pathways, the activated AKT can promote the growth and proliferation of tumor cells, inhibit cell apoptosis, and promote 
the invasion and metastasis of tumor cells [6,7]. Dysregulation of EGFR/PI3K/AKT/mTOR pathway has an important effect in the formation of lung cancer. AKT was reported to be activated in most of the lung cancers and its phosphorylation or overexpression is related to the poor prognosis of NSCLC patient. Researches that combine conventional chemotherapy with AKT kinase inhibitory have been proven valid in delaying chemotherapeutic resistance in NSCLC [8].

KRAS gene is an important downstream molecule in the EGFR signal transduction pathway, and about $15 \%-30 \%$ NSCLC has KRAS mutations [9]. The mutations mostly occur in the point mutation of exon 2 or exon 3 of KRAS, which are common in patients with heavy smoking, and seldom co-exist with EGFR mutations. Studies have reported that KRAS mutation can be the negative factor for the prognosis of NSCLC patient, and KRAS mutation has been proven to be negative related to the treatment effects of Erlotinib and Gefitinib. The cause may be that KRAS mutation results in ERK and/or AKT activation which is associated with drug resistance to EGFR TKIs [10].

Tumor necrosis factor superfamily (TNFSF) plays an important role in the induction of apoptosis. TNF-related apoptosis-inducing ligand (TRAIL)/TRAIL-R are the essential ligand and its associated receptors of TNFSF, respectively [11]. TRAIL combines with death receptors DR4 and DR5, and initiates apoptosis. TRAIL combines with decoy receptors DcR1 and DcR2 and protects cells against TRAIL apoptosis $[12,13]$. The intracellular region of DR5 contains a death domain, which is highly expressed in a variety of tumor tissues including NSCLC. Studies have shown that at $37^{\circ} \mathrm{C}$ TRAIL has the maximum binding force with DR5 [14]. This characteristic allows DR5 to surpass other receptors and has the highest affinity with TRAIL when the cells of body are at the most suitable survival temperature of $37^{\circ} \mathrm{C}$, thus maximizing the function of TRAIL-induced apoptosis. Lacking intracellular death domain, DcR1 competitively prevents the combination of TRAIL and DR5 and plays a role in inhibiting apoptosis [15]. The change of DR/DcR expression level will regulate the sensitivity of cells to TRAIL-mediated apoptosis. The expression of TRAIL receptors and their intensities will to a large extent affect the future clinical application of TRAIL. In NSCLC, the expression of DR4, DR5, and TRAIL in poorly differentiated tumors is normally increased, and the expression of DR5 is associated with patient's death [16]. This provides a basis for TRAIL and agonistic antibodies of targeted DR4 or DR5 in treating NSCLC. Studies have shown that a variety of NSCLC cells are resistant to TRAIL [17]. TRAIL resistance largely comes from the downward expression of DR5 as well as the activation of AKT phosphorylation. Shrader etc. reported that Gefitinib could regulate the activity of AKT, down-regulate the expression of XIAP, and further enhance TRAIL-induced apoptosis in patients with NSCLC [18]. The activation of death receptor pathway can directly induce the apoptosis of tumor cells, which may provide a new mode of treating NSCLC, and further overcome drug resistance in cells. But the expression and distribution of TRAIL receptor in NSCLC are still not clear, and need further research.

In this study, we detected EGFR or KRAS mutation and the protein expression of p-AKT, DR5, and DcR1 in patients with NSCLC. In addition, the correlations of the above genetic mutations and protein expressions to the clinicopathological features were also investigated to provide a certain basis for the clinical application of TRAIL and death receptor agonistic antibody.

\section{Patients and methods}

Study population. 82 cases of NSCLC confirmed by surgery and pathology were collected from the Second Affiliated Hospital of Harbin Medical University from March 2012 to December 2015. All patients joined this study were approved by the ethics committee of the Second Affiliated Hospital of Harbin Medical University. Each sample was divided into two parts. Tumor tissue was taken from one part of the sample in vitro within $30 \mathrm{~min}$, and quickly put into $-180^{\circ} \mathrm{C}$ liquid nitrogen, and then preserved at $-80^{\circ} \mathrm{Clow}$-temperature refrigerator. The other part of the sample was fixed in $10 \%$ formalin solution. The specimen was embedded in paraffin, and sectioned at $4 \mu \mathrm{m}$ thickness. The above two parts of the specimen all used pericarcinous lung tissue as the control (cancer margin distance $>2 \mathrm{~cm}$, microscopy showed no cancerous invasion and metastasis). Patients had not received chemotherapy or radiotherapy before surgery. Patients aged 33-72 years old, average age 52.35 years old. The TNM classification was determined according to the $7^{\text {th }}$ version of the International Association for the Study of Lung Cancer Staging System [19]. Detailed clinical and pathological data was shown in Table 1.

Detection of EGFR and KRAS genetic mutation by $x$ TAG Liquichip Technology (xTAG-LCT). DNA extraction kit was used to extract DNA from tissue sample. Gene segments with common alleles in various gene exons were obtained by using multiplex polymerase chain reaction (PCR). PCR reaction system contained $13.8 \mu \mathrm{l} \mathrm{H} \mathrm{O}, 10 \mu \mathrm{l} 5 \times \mathrm{PCR}$ buffer, $4 \mu \mathrm{l}$ $25 \mathrm{mM} \mathrm{MgCl}, 2 \mu \mathrm{l}$ dNTP mixture, various gene exon primers mixture $10 \mu \mathrm{l}, 0.2 \mu \mathrm{l}$ DNA polymerase, and $10 \mu \mathrm{l}$ sample. PCR reaction condition was annealing temperature at $52{ }^{\circ} \mathrm{C}$ for 30 cycles. Then PCR product was digested by exonuclease and hydrolysed by alkaline phosphatase to remove redundant primers and dNTP. The reaction system contained $0.5 \mu \mathrm{l}$ exonuclease, $0.5 \mu \mathrm{l}$ alkaline phosphatase, $10 \mu \mathrm{l} 2 \times$ buffer, $9 \mu \mathrm{l}$ PCR product, and enzyme hydrolysis reaction at $37^{\circ} \mathrm{C}$ for 2 hours. Then with the specific sequence on the allele specific primer extension (ASPE), the product specifically identified each allele and formed the extension product. ASPE reaction system contained $7.8 \mu \mathrm{l} \mathrm{H}, \mathrm{O}, 2 \mu \mathrm{l} 10 \times \mathrm{PCR}$ buffer, $0.5 \mu \mathrm{l} 25 \mathrm{mM} \mathrm{MgCl}$, $1 \mu \mathrm{lNTP}$ (without dCTP) mixture, $0.5 \mu$ l biotinylated dCTP, $5 \mu \mathrm{l}$ various allele primers mixture, $0.2 \mu \mathrm{l}$ DNA polymerase, and $3 \mu$ l enzyme digestion hydrolysis product. ASPE reaction condition was annealing temperature at $56^{\circ} \mathrm{C}$ for 30 cycles. Tag sequence on ASPE primer specifically combined with 
Table 1. Clinicopathological Characteristics of patients with NSCLC $(\mathrm{N}=\mathbf{8 2})$

\begin{tabular}{lc}
\hline Characteristics & No. of patients (\%) \\
\hline Age(years) & \\
$\quad$ Median(range), y & $54(33-72)$ \\
$\geq \mathbf{6 0}$ & $36(43.90)$ \\
$<\mathbf{6 0}$ & $46(56.10)$ \\
Gender & \\
Male & $45(54.88)$ \\
Female & $37(45.12)$ \\
Stage & \\
I & $27(32.93)$ \\
II & $30(36.59)$ \\
III & $25(30.49)$ \\
Histopathology & \\
AD & $47(57.32)$ \\
SC & $35(42.68)$ \\
Tumor differentiation & \\
Well differentiated & $16(19.51)$ \\
Moderately differentiated & $29(35.37)$ \\
Poorly differentiated & $37(39.9)$ \\
Lymph node metastasis & \\
Yes & $44(53.66)$ \\
No & $38(46.34)$ \\
Smoking status & \\
Yes & $42(51.22)$ \\
No & $40(48.78)$ \\
\hline AD, adenocarcinomas &
\end{tabular}

$\mathrm{AD}$, adenocarcinoma; $\mathrm{SC}$, squamous cell carcinoma

Anti-Tag sequence on polystyrene microsphere, which was hybridization reaction. The hybridization reaction system contained $12 \mu \mathrm{l}$ microspheres, $33 \mu \mathrm{l}$ hybridization solution, and $5 \mu \mathrm{l}$ ASPE product. The hybrid system went through denaturation at $95^{\circ} \mathrm{C}$ for 3 minutes. After hybridization at $37^{\circ} \mathrm{C}$ for 30 minutes, $25 \mu \mathrm{S} \mathrm{SA-PE} \mathrm{working} \mathrm{solution} \mathrm{were} \mathrm{added} \mathrm{to}$ the system, reaction was continued at $37^{\circ} \mathrm{C}$ for 10 minutes. Luminex 200 system was applied to analyze the fluorescence value of each sample.

Primers for EGFR and KRAS gene target sequence were designed and synthesized by Guangzhou Surexam Biotechnology Company. Primer sequences were shown in Supplementary Tables 1 and 2.

Quantitative real-time PCR. Total RNA from the human tissue samples were extracted using TRIzol reagent (Invitrogen). Reverse transcription reaction with $1 \mu \mathrm{g}$ of total RNA in $100 \mu \mathrm{l}$ was carried out using M-MLV Reverse Transcriptase (D2640A, Takara, Japan). For quantitative PCR, $10 \mu \mathrm{l}$ SYBR Premix Ex Taq (Takara, Japan) with $10 \mu \mathrm{M}$ of each primer and $10 \mathrm{ng}$ cDNA template in $20 \mu \mathrm{l}$ of reaction volume was applied. Primers used for amplification were designed as: AKT, forward, 5'- CTTGCTTTCAGGGCTGCTCA- $3^{\prime}$ and reverse, TACACGTGCTGCCACACGATAC; DR5, forward, 5'-CACCACGACCAGAAACACAG-3' and reverse, 5'-AATCACCGACCTTGACCATC-3; DcR1, forward, $5^{\prime}$-TGCCTGAATCATACTCCTT-3' and reverse, $5^{\prime}$-CCTGTGAATGTTCCTGGGT-3'; $\beta$-actin (as an internal control), forward, $5^{\prime}$-CCTGTACGCCAACACAGTGC- $3^{\prime}$ and reverse, $5^{\prime}$ - ATACTCCTGCTTGCTGATCC-3'. All reactions were performed on the TaKaRa PCR Thermal Cycler Dice. To calculate values of mRNA levels, 2(-Delta Delta $\mathrm{C}(\mathrm{T})$ ) method was used, where CT is the threshold cycle. Target gene mRNA levels were normalized to that of actin mRNA in the same sample.

Antibodies and western blotting. Anti-AKT, anti-phospho-AKT, anti-DR5, anti-DcR1 and anti-GAPDH antibodies were purchased from Santa Cruz Biotechnology (Santa Cruz, CA, USA). Goat anti-mouse and goat anti-rabbit IgG were purchased from Cell Signaling Technology (Beverly, MA, USA). Total protein lysates were obtained from tissue using lysis buffer including $50 \mathrm{mM}$ Tris (pH 7.5), $150 \mathrm{mM} \mathrm{NaCl}$, $1 \%$ Triton X-100, $0.5 \%$ sodium deoxycholate, $0.1 \%$ SDS, and one Complete Mini Protease Inhibitor Cocktail tablet (Roche, Indianapolis, IN). The lysates were centrifuged at $10,000 \mathrm{x} \mathrm{g}$ for 30 minutes at $4{ }^{\circ} \mathrm{C}$ and the supernatant was collected. Then total proteins were extracted and protein concentrations were determined by Bradford assay. Took $100 \mu \mathrm{g}$ sample, denatured for 5 minutes, and used $12 \%$ sodium dodecyl sulfate-polyacrylamide gel electrophoresis (SDS-PAGE) gels. The separated proteins were transferred onto PVDF membranes (IPVH00010, Millipore). After electro-transfer, membranes were blocked with $5 \%$ nonfat milk in TBS-T buffer (20 mM Tris-HCl, pH 8.0, $150 \mathrm{mM} \mathrm{NaCl}, 0.05 \%$ Tween 20). Added the first antibody, incubated, and shook overnight at $4{ }^{\circ} \mathrm{C}$. After washing three times with TBST, added the second antibody labeled with horseradish peroxidase, and incubated at room temperature for 1 hour. Optical density of the bands was determined using the LabWork software (UVP Laboratory Products, CA). All experiments were repeated at least three times.

Statistical analysis. The association between EGFR-activating mutations or KRAS mutations and clinicopathological factors was evaluated using the $\chi^{2}$ test. The correlations between the mRNA and protein expression of factors examined and clinicopathological features were evaluated by Student's t-test. In order to assess the significant differences between mutation status and mRNA or protein expression of factors, we performed one-way analysis of variance (ANOVA). Tukey's test was used for post-hoc analysis. The measurement data was expressed as means with standard deviation (SD). A value of $P<0.05$ was considered as statistically significant.

\section{Results}

EGFR and KRAS mutation analysis. 36 patients out of 82 patients had EGFR mutations, accounting for $43.90 \%$, among which exon 18 mutation 2 cases (2.44\%): G719A 1 case, G719S 1 case; exon 19 deletion 15 cases (18.29\%); exon 20 threonine to methionine codon 790 (T790M) mutation 
3 cases (3.66\%); exon 21 leucine to arginine codon 858 (L858R) missense mutation 16 cases (19.51\%). No patient with multiple EGFR mutations was found. EGFR-activating mutations (exon 19 deletion and L858R missense mutation in exon 21) accounted for $86.11 \%(31 / 36)$ of all patients, and other rare mutations accounted for $13.89 \%$. The analysis of relationship between EGFR-activating mutations and clinicopathological data showed that EGFR-activating mutations were associated with gender, pathological type, and smoking status (Table 2). $67.57 \%(25 / 37)$ women had EGFR-activating mutations, which was significantly higher than that of male patients $[13.33 \%$ $(6 / 45)]\left(\chi^{2}=25.401, P<0.001\right)$. The EGFR-activating mutation rate of patient with adenocarcinoma was significantly higher than that of squamous cell carcinoma $(51.06 \%$ vs. $20.00 \%$, $\left.\chi^{2}=8.233, P=0.004\right)$. The EGFR-activating mutation rate of patient with smoking history was significantly lower than that of patient with non-smoking history $(23.81 \% v s .52 .50 \%$, $\chi^{2}=7.172, P=0.007$ ) (Table 2).

Nine patients out of 82 patients had KRAS mutations (10.98\%), among which exon 2 mutation 4 cases (4.88\%), exon 3 mutation 5 cases $(6.10 \%)$. KRAS mutations were relevant to the smoking status of patient. KRAS mutation ratio was significantly higher in patients with smoking history than those without smoking history $\left(19.05 \%\right.$ vs. $2.50 \%, \chi^{2}=5.742$, $P=0.017$ ) (Table 2).
The mRNA expression of AKT, DR5 and DcR1 in NSCLC tissue and their relationships with clinicopathological factors. The mRNA expression of AKT, DR5 and DcR1 in 82 cases of lung cancer and pericarcinous tissue was detected by Real-time PCR. As shown in Figure 1, the relative amount of AKT mRNA in NSCLC tissue was $0.107 \pm 0.009$, while the relative amount of AKT mRNA in pericarcinous tissue was $0.099 \pm 0.008$, so the difference was statistically significant $(\mathrm{t}=6.372, \mathrm{P}<0.001)$. The expression of AKT mRNA in NSCLC tissue was associated with lung cancer staging, tumor differentiation, and lymph node metastasis (Table 3). The relative amount of DR5 mRNA in NSCLC tissue was $0.093 \pm 0.008$, which was significantly higher than the relative amount of DR5 mRNA in pericarcinous tissue $(0.088 \pm 0.007)(\mathrm{t}=4.391, \mathrm{P}<0.001)$ (Figure 1). The expression of DR5 mRNA in phase III NSCLC and poorly differentiated tumor was significantly higher than that in phase I + II and high and median differentiated tumor (Table 3), whereas the relative amount of DcR1 mRNA in NSCLC tissue was $0.091 \pm 0.009$, which was significantly lower than that in the paired pericarcinous tissue $(0.097 \pm 0.006)(t=5.234, \mathrm{P}<0.001)$ (Figure 1$)$. The expression of DcR1 mRNA in phase III NSCLC and poorly differentiated tumor was significantly lower than that in phase I + II and high and median differentiated tumor (Table 3 ).

Table 2. The correlation between EGFR active mutation (exons 19 and 21) or KRAS mutation and clinicopathological factors

\begin{tabular}{|c|c|c|c|c|c|c|c|}
\hline \multirow[t]{2}{*}{ Characteristics } & \multirow[t]{2}{*}{$\mathbf{N}$} & \multicolumn{3}{|c|}{ EGFR } & \multicolumn{3}{|c|}{ KRAS } \\
\hline & & Mutation (\%) & $\chi^{2}$ & $\mathbf{P}$ & Mutation (\%) & $\chi^{2}$ & $\mathbf{P}$ \\
\hline \multicolumn{8}{|l|}{ Age(years) } \\
\hline$\geq 60$ & 36 & $12(33.33)$ & & & $4(11.11)$ & & \\
\hline$<60$ & 46 & $19(41.30)$ & 0.546 & 0.460 & $5(10.87)$ & 0.001 & 0.972 \\
\hline \multicolumn{8}{|l|}{ Gender } \\
\hline Male & 45 & $6(13.33)$ & & & $6(13.33)$ & & \\
\hline Female & 37 & $25(67.57)$ & 25.401 & $<0.001$ & $3(8.11)$ & 0.567 & 0.451 \\
\hline \multicolumn{8}{|l|}{ Stage } \\
\hline I & 27 & $10(37.04)$ & & & $3(11.11)$ & & \\
\hline II & 30 & $12(40.00)$ & & & $4(13.33)$ & & \\
\hline III & 25 & $9(36.00)$ & 0.103 & 0.950 & $2(8.00)$ & 0.398 & 0.820 \\
\hline \multicolumn{8}{|l|}{ Histopathology } \\
\hline $\mathrm{AD}$ & 47 & $24(51.06)$ & & & $5(10.64)$ & & 0.204 \\
\hline SC & 35 & $7(20.00)$ & 8.233 & 0.004 & $4(11.43)$ & 0.013 & 0.910 \\
\hline \multicolumn{8}{|l|}{ Tumor differentiation } \\
\hline Well differentiated & 16 & $6(39.5)$ & & & $2(12.50)$ & & \\
\hline Moderately differentiated & 29 & $10(34.48)$ & & & $4(13.79)$ & & \\
\hline Poorly differentiated & 37 & $15(40.54)$ & 0.255 & 0.881 & $3(8.11)$ & 0.585 & 0.746 \\
\hline \multicolumn{8}{|l|}{ Lymph node metastasis } \\
\hline Yes & 44 & $17(38.64)$ & & & $4(9.09)$ & & \\
\hline No & 38 & $14(36.84)$ & 0.028 & 0.867 & $5(13.16)$ & 0.345 & 0.557 \\
\hline \multicolumn{8}{|l|}{ Smoking status } \\
\hline Yes & 42 & $10(23.81)$ & & & $8(19.05)$ & & \\
\hline No & 40 & $21(52.50)$ & 7.172 & 0.007 & $1(2.50)$ & 5.742 & 0.017 \\
\hline
\end{tabular}

$\mathrm{AD}$, adenocarcinoma; $\mathrm{SC}$, squamous cell carcinoma 


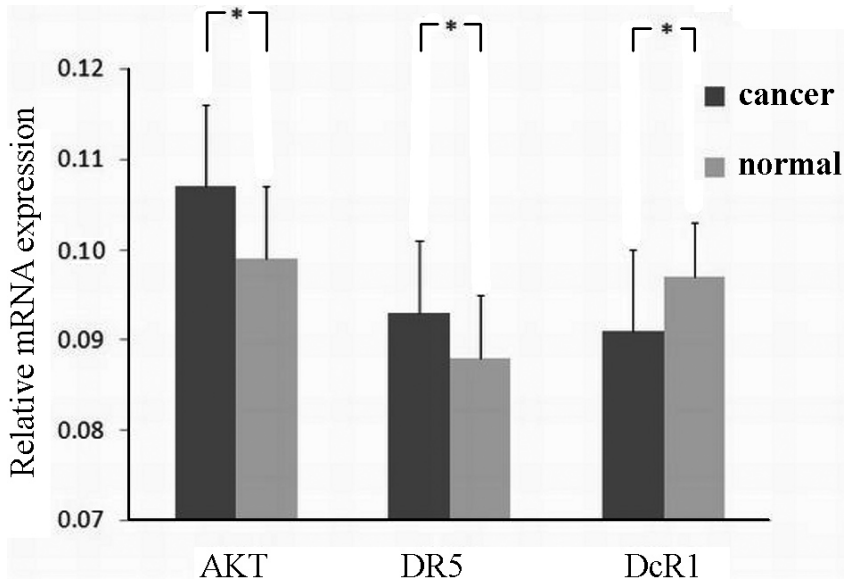

Figure 1. The mRNA expression of AKT, DR5 and DCR1 in NSCLC tissue. The mRNA expression was detected by realtime PCR. Cancer refers lung cancer tissue. Normal refers to pericarcinous tissue. The figure is representative of one of three independent experiments. This panel reflects the ratios of AKT, DR5 and DCR1 to $\beta$-actin, respectively. Compared with the normal group, ${ }^{\star} \mathrm{P}<\mathbf{0 . 0 1}$.

The protein expression of AKT, p-AKT, DR5 and DcR1 in NSCLC tissue and their relationships with clinicopathological factors. The protein expression of AKT, p-AKT, DR5 and DcR1 in 82 cases of frozen lung cancer and pericarcinous tissue was detected by Western Blotting.
As shown in Figure 2A, the expression of AKT, p-AKT and DR5 in lung cancer tissue was significantly higher than that in pericarcinous tissue, while the expression of DcR1 was significantly lower than that in pericarcinous tissue. Film scanning analysis showed that the relative amount of AKT protein in NSCLC tissue was $0.65 \pm 0.09$, while the relative amount of $\mathrm{AKT}$ protein in pericarcinous tissue was $0.30 \pm 0.04$, so the difference was statistically significant $(\mathrm{t}=3.007, \mathrm{P}=0.004)$ (Figure $2 \mathrm{~B})$. The relative amount of $\mathrm{p}$-AKT protein in NSCLC tissue was $0.70 \pm 0.11$, while the relative amount of $\mathrm{p}$-AKT protein in pericarcinous tissue was $0.36 \pm 0.03$, so the difference was statistically significant $(\mathrm{t}=2.786, \mathrm{P}=0.007)$ (Figure $2 \mathrm{~B})$. The expression of $\mathrm{AKT}$ and $\mathrm{p}-\mathrm{AKT}$ protein in NSCLC tissue was associated with lung cancer staging, tumor differentiation, and lymph node metastasis (Table 4). The relative amount of DR5 protein in NSCLC tissue was $0.69 \pm 0.11$, which was significantly higher than the relative amount of DR5 protein in pericarcinous tissue $(0.32 \pm 0.06)(\mathrm{t}=2.774, P=0.007)$ (Figure 2B). The expression of DR5 protein in phase III NSCLC and poorly differentiated tumor was significantly higher than that in phase I + II and high and median differentiated tumor (Table 4), whereas the relative amount of DcR1 protein in NSCLC tissue was $0.27 \pm 0.05$, which was significantly lower than that in the paired pericarcinous tissue $(0.67 \pm 0.13)$ $(\mathrm{t}=2.738, P=0.008)$ (Figure $2 \mathrm{~B})$. The expression of DcR1 protein in phase III NSCLC and poorly differentiated tumor

Table 3. The correlation between AKT, DR5 and DcR1 mRNA expression and clinicopathological factors

\begin{tabular}{|c|c|c|c|c|c|c|c|c|c|c|}
\hline \multirow[t]{2}{*}{ Characteristics } & \multirow[t]{2}{*}{$\mathbf{N}$} & \multicolumn{3}{|c|}{ AKT } & \multicolumn{3}{|c|}{ DR5 } & \multicolumn{3}{|c|}{ DcR1 } \\
\hline & & $\bar{x}_{ \pm \mathrm{s}}$ & $\mathrm{t}$ & $\mathrm{P}$ & $\bar{x}_{ \pm \mathrm{s}}$ & $\mathrm{t}$ & $\mathrm{P}$ & $\bar{x}_{ \pm s}$ & $\mathrm{t}$ & $\mathrm{P}$ \\
\hline \multicolumn{11}{|l|}{ Age(years) } \\
\hline$\geq 60$ & 36 & $0.071 \pm 0.002$ & & & $0.084 \pm 0.005$ & & & $0.103 \pm 0.006$ & & \\
\hline$<60$ & 46 & $0.072 \pm 0.003$ & 1.722 & 0.089 & $0.083 \pm 0.003$ & 1.124 & 0.265 & $0.101 \pm 0.006$ & 1.498 & 0.138 \\
\hline \multicolumn{11}{|l|}{ Gender } \\
\hline Male & 45 & $0.093 \pm 0.008$ & & & $0.101 \pm 0.008$ & & & $0.095 \pm 0.007$ & & \\
\hline Female & 37 & $0.091 \pm 0.002$ & 1.482 & 0.142 & $0.104 \pm 0.009$ & 1.597 & 0.114 & $0.098 \pm 0.008$ & 1.811 & 0.074 \\
\hline \multicolumn{11}{|l|}{ Stage } \\
\hline I+II & 57 & $0.071 \pm 0.006$ & & & $0.067 \pm 0.006$ & & & $0.084 \pm 0.007$ & & \\
\hline III & 25 & $0.075 \pm 0.004$ & 3.046 & 0.003 & $0.072 \pm 0.006$ & 3.476 & 0.001 & $0.079 \pm 0.005$ & 3.225 & 0.002 \\
\hline \multicolumn{11}{|l|}{ Histopathology } \\
\hline AD & 47 & $0.093 \pm 0.007$ & & & $0.075 \pm 0.008$ & & & $0.106 \pm 0.011$ & & \\
\hline SC & 35 & $0.095 \pm 0.008$ & 1.204 & 0.232 & $0.077 \pm 0.002$ & 1444 & 0.153 & $0.103 \pm 0.009$ & 1.318 & 0.191 \\
\hline \multicolumn{11}{|l|}{ Tumor differentiation } \\
\hline Well - Moderately differentiated & 45 & $0.068 \pm 0.007$ & & & $0.065 \pm 0.004$ & & & $0.083 \pm 0.007$ & & \\
\hline Poorly differentiated & 37 & $0.072 \pm 0.006$ & 2.745 & 0.007 & $0.069 \pm 0.006$ & 3.607 & 0.001 & $0.078 \pm 0.004$ & 3.858 & $<0.001$ \\
\hline \multicolumn{11}{|l|}{ Lymph node metastasis } \\
\hline Yes & 44 & $0.086 \pm 0.008$ & & & $0.098 \pm 0.007$ & & & $0.106 \pm 0.006$ & & \\
\hline No & 38 & $0.081 \pm 0.005$ & 3.332 & 0.001 & $0.096 \pm 0.006$ & 1.378 & 0.172 & $0.103 \pm 0.009$ & 1.798 & 0.076 \\
\hline \multicolumn{11}{|l|}{ Smoking status } \\
\hline Yes & 42 & $0.094 \pm 0.005$ & & & $0.105 \pm 0.007$ & & & $0.086 \pm 0.008$ & & \\
\hline No & 40 & $0.096 \pm 0.006$ & 1.643 & 0.104 & $0.108 \pm 0.009$ & 1.690 & 0.095 & $0.084 \pm 0.009$ & 1.065 & 0.290 \\
\hline
\end{tabular}

$\mathrm{AD}$, adenocarcinoma; $\mathrm{SC}$, squamous cell carcinoma 
A

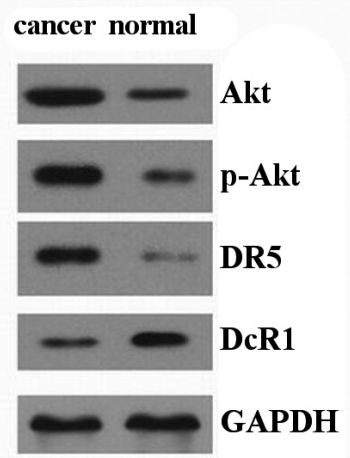

B

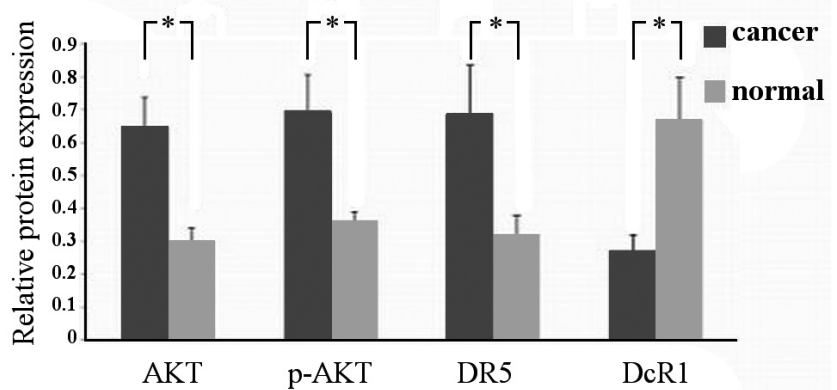

Figure 2. The protein expression of AKT, p-AKT, DR5 and DcR1 in NSCLC tissue. A: The protein expression was detected by western blot with corresponding antibodies. Cancer refers lung cancer tissue. Normal refers to pericarcinous tissue. The figures are representatives of one of three independent experiments. B: This panel reflects the ratios of AKT, p-AKT, DR5 and DcR1 to GAPDH, respectively. Compared with the normal group, ${ }^{\star} \mathbf{P}<0.01$.

was significantly lower than that in phase I + II and high and median differentiated tumor (Table 4).

The relationship of EGFR or KRAS mutation Status to expression of AKT, p-AKT, DR5 and DcR1. According to the genetic state of EGFR and KRAS in patients with lung cancer, NSCLC tissue samples were divided into three groups: an EGFR-activating mutation group, a KRAS mutation group, and a group that was negative for both biomarkers. Figure 3 showed that the expression of AKT mRNA in NSCLC tissue with different EGFR/KRAS mutation status had significant difference $(\mathrm{F}=54.065, P<0.001)$. The expression of AKT mRNA in NSCLC tissue with EGFR-activating mutations $(P<0.001)$ and KRAS mutations $(P<0.001)$ was significantly higher than that in NSCLC tissue with EGFR/KRAS wild type. There was no significant difference between the mRNA expression of AKT in NSCLC tissue with EGFR-activating mutations and KRAS mutations $(P=0.211)$. However, the mRNA expression of DR5 and DcR1 in NSCLC tissue with different EGFR or KRAS mutation status showed no significant difference (Figure 3). Figure 4

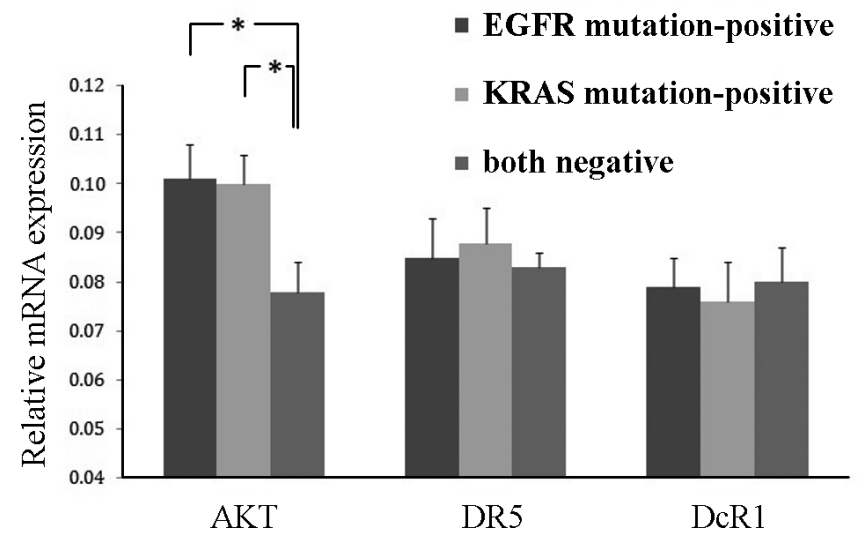

Figure 3. The mRNA expression of AKT, DR5 and DcR1 according to different EGFR and KRAS mutation status. This panel reflects the ratios of AKT, DR5 and DcR1 to $\beta$-actin, respectively. Compared with the both negative group, ${ }^{\star} \mathrm{P}<0.01$, respectively.

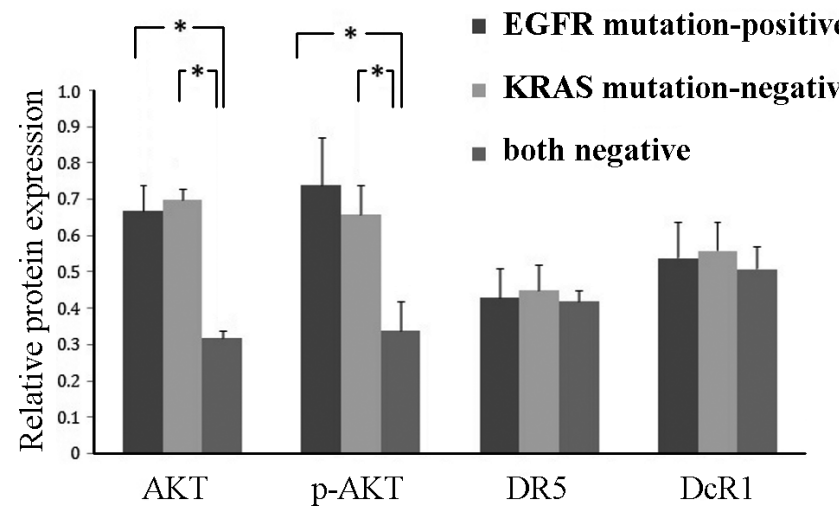

Figure 4. The protein expression of AKT, p-AKT, DR5 and DcR1 according to different EGFR and KRAS mutation status. This panel reflects the ratios of AKT, p-AKT, DR5 and DcR1 to GAPDH, respectively. Compared with the both negative group, ${ }^{\star} \mathrm{P}<0.01$, respectively.

showed that the expression of AKT and p-AKT protein in NSCLC tissue with different EGFR/KRAS mutation status had significant difference $(\mathrm{F}=95.951, \mathrm{P}<0.001 ; \mathrm{F}=40.086, \mathrm{P}<0.001$, respectively). The expression of AKT and p-AKT protein in NSCLC tissue with EGFR-activating mutations (both $\mathrm{P}<0.001$ ) and KRAS mutations (both $\mathrm{P}<0.001$ ) was significantly higher than that in NSCLC tissue with EGFR/KRAS wild type. There was no significant difference between the protein expression of AKT and p-AKT in NSCLC tissue with EGFR-activating mutations and KRAS mutations $(P=0.104)$. However, the protein expression of DR5 and DcR1 in NSCLC tissue with different EGFR or KRAS mutation status showed no significant difference (Figure 4). The results indicated that EGFR and KRAS mutation status was associated with the expression of AKT and p-AKT, and had nothing to do with the expression of DR5 and DcR1. 
Table 4. The correlation between AKT, p-AKT, DR5 and DcR1 protein expression and clinicopathological factors

\begin{tabular}{|c|c|c|c|c|c|c|c|c|c|c|}
\hline \multirow[t]{2}{*}{ Characteristics } & \multirow[t]{2}{*}{$\mathbf{N}$} & \multicolumn{3}{|c|}{ p-AKT } & \multicolumn{3}{|c|}{ DR5 } & \multicolumn{3}{|c|}{ DcR1 } \\
\hline & & $\bar{x}_{ \pm \mathrm{s}}$ & $\mathbf{t}$ & $\mathbf{P}$ & $\bar{x}_{ \pm \mathrm{s}}$ & $\mathbf{t}$ & $\mathbf{P}$ & $\bar{x}_{ \pm \mathrm{s}}$ & $\mathbf{t}$ & $\mathbf{P}$ \\
\hline \multicolumn{11}{|l|}{ Age(years) } \\
\hline$\geq 60$ & 36 & $0.53 \pm 0.11$ & & & $0.48 \pm 0.07$ & & & $0.53 \pm 0.15$ & & \\
\hline$<60$ & 46 & $0.56 \pm 0.09$ & 1.359 & 0.178 & $0.46 \pm 0.05$ & 1.509 & 0.135 & $0.55 \pm 0.14$ & 0.622 & 0.536 \\
\hline \multicolumn{11}{|l|}{ Gender } \\
\hline Male & 45 & $0.50 \pm 0.12$ & & & $0.55 \pm 0.14$ & & & $0.46 \pm 0.12$ & & \\
\hline Female & 37 & $0.51 \pm 0.12$ & 0.376 & 0.708 & $0.52 \pm 0.13$ & 0.997 & 0.322 & $0.43 \pm 0.13$ & 1.085 & 0.281 \\
\hline \multicolumn{11}{|l|}{ Stage } \\
\hline I+II & 57 & $0.44 \pm 0.08$ & & & $0.49 \pm 0.04$ & & & $0.67 \pm 0.14$ & & \\
\hline III & 25 & $0.79 \pm 0.14$ & 14.405 & $<0.001$ & $0.77 \pm 0.15$ & 13.215 & 0.000 & $0.40 \pm 0.08$ & 9.023 & $<0.001$ \\
\hline \multicolumn{11}{|l|}{ Histopathology } \\
\hline AD & 47 & $0.61 \pm 0.15$ & & & $0.56 \pm 0.08$ & & & $0.56 \pm 0.10$ & & \\
\hline SC & 35 & $0.58 \pm 0.09$ & 1.050 & 0.297 & $0.59 \pm 0.10$ & 1.509 & 0.135 & $0.59 \pm 0.11$ & 1.288 & 0.202 \\
\hline \multicolumn{11}{|l|}{ Tumor differentiation } \\
\hline Well - Moderately differentiated & 45 & $0.34 \pm 0.08$ & & & $0.55 \pm 0.09$ & & & $0.63 \pm 0.07$ & & \\
\hline Poorly differentiated & 37 & $0.74 \pm 0.13$ & 17.194 & $<0.001$ & $0.61 \pm 0.06$ & 3.471 & 0.001 & $0.58 \pm 0.06$ & 2.745 & 0.007 \\
\hline \multicolumn{11}{|l|}{ Lymph node metastasis } \\
\hline Yes & 44 & $0.65 \pm 0.14$ & & & $0.58 \pm 0.04$ & & & $0.59 \pm 0.04$ & & \\
\hline No & 38 & $0.57 \pm 0.07$ & 3.194 & 0.002 & $0.56 \pm 0.05$ & 1.006 & 0.318 & $0.60 \pm 0.03$ & 1.264 & 0.210 \\
\hline \multicolumn{11}{|l|}{ Smoking status } \\
\hline Yes & 42 & $0.45 \pm 0.12$ & & & $0.51 \pm 0.06$ & & & $0.53 \pm 0.07$ & & \\
\hline No & 40 & $0.40 \pm 0.14$ & 1.739 & 0.086 & $0.54 \pm 0.10$ & 1.657 & 0.102 & $0.55 \pm 0.06$ & 1.386 & 0.170 \\
\hline
\end{tabular}

$\mathrm{AD}$, adenocarcinoma; $\mathrm{SC}$, squamous cell carcinoma

\section{Discussion}

The treatment effect and prognosis of NSCLC patients, which were of the same clinical stage, the same pathological type, and the same therapy, were commonly significantly different. The difference of treatment effect and prognosis may be due to the existence of genetic heterogeneity, such as the different mutation status of EGFR and KRAS genes. Researches showed that after applying Gefitinib and Erlotinib on behalf of TKI therapy, the remission rate of NSCLC patients with EGFR exon 19 deletion and exon 21 L858R point mutation was significantly higher than that of EGFR wild-type patients [20]. However, similar to chemotherapy, TKI therapy also inevitably faced the issue of drug resistance. Moreover, resistant to various TKI, NSCLC patients with KRAS mutations often predict worse treatment effect and prognosis. This research selected NSCLC patients with different EGFR and KRAS genetic state, analyzed the relationship of EGFR and KRAS genetic state in lung cancer tissue to the expression of p-AKT and TRAIL receptor, and investigated further opportunities for improving the treatment effect and prognosis of NSCLC.

Our research found that 36 patients out of 82 patients had EGFR mutations at different loci, accounting for $43.90 \%$, which was in accordance with the reported Asian EGFR mutation rate (39\%-64\%) [21]. EGFR mutation mainly focused on the deletion of exon 19 and L858R missense mutation of exon 21 (about $86 \%$ ), that was relatively close to the literature's reported $90 \%$ [22]. Further analysis of the relationship between EGFR-activating mutations and clinicopathological characteristics showed that the incidence of EGFR-activating mutations in female, adenocarcinoma and non-smoking patients was significantly increased, which was consistent with previous studies [23, 24]. However, although many researches have shown that EGFR mutation was common in Asian female NSCLC patients, and the treatment effectiveness of EGFR TKIs in Asian female NSCLC patients was better than that of male patients with NSCLC [25], so from the aspect of clinical sign, it seemed that EGFR TKIs had better treatment effect in Asian female patients. However, further analysis showed that, in Europe and the United States, more than $80 \%$ of the female patients with NSCLC were smokers, while the situation in China was different from that in Western countries, in China most of the women were non-smokers, indicating that the difference of EGFR TKIs treatment effect between men and women might mainly be due to the impact of whether smoking or not, and not much associated with gender. In addition, in NSCLC patients, KRAS gene mutation was a common gene abnormality associated with smoking. Our research also confirmed the correlation between KRAS gene mutation and smoking in NSCLC patients. Since KRAS mutation was relevant to the poor prognosis of NSCLC [26], therefore, it 
might be speculated that among the many clinicopathological factors associated with the prognosis of NSCLC patients, smoking seemed to play a more vital role. The smoking history of patient with NSCLC had a serious impact on the treatment effect of EGFR TKIs.

EGFR in lung cancer cells was often overexpressed or mutated, and was in an abnormal state of activation. EGFR was activated or autophosphorylated by the ligand EGF, activating the intracellular signaling proteins, mainly the RAS- RAF- MEK- MAPK and PI3K- AKT signal pathway. The inhibition of phosphorylation of ERK or AKT can block MAPK, AKT signaling pathway, respectively, which can further blocklung cancer cell proliferation, angiogenesis, invasion, metastasis, and other processes induced by EGFR activation [27]. Besides, the phosphorylation of AKT was also one of the important causes of chemoresistance. Studies have shown that the combined application of PI3K/AKT pathway inhibitors and conventional chemotherapy can delay the occurrence of chemotherapy resistance [28]. EGFR TKIs can inhibit the activity of this proliferation pathway and restart cell apoptosis. So we detected the expression of AKT and its relevant phosphorylated form $\mathrm{p}$-AKT in lung cancer and normal tumor-adjacent lung tissues, respectively, and analyzed the relationship among gene expression, clinical pathological factors, and driver gene status. Our research indicated that no matter the mRNA level or protein level of AKT expression in lung cancer tissues was significantly higher than that in the normal cancer-adjacent tissues, and the expression was much higher in the NSCLC tissues of late stage, poorly differentiation, and with lymph node metastasis, suggesting that the AKT gene exerted its biological functions through transcriptional regulation; while in lung cancer tissues, the phosphorylation level of AKT protein was significantly higher than that in adjacent tissues, and also the expression was much higher in the NSCLC tissues of late stage, poorly differentiation, and with lymph node metastasis, indicating the expression of AKT and its phosphorylated form may be positively correlated with tumor invasion, metastasis, and prognosis. EGFR activity mutation or KRAS mutation could significantly enhance the expression of mRNA and protein in AKT and the phosphorylation of AKT in NSCLC tissues, indicating that the activation of EGFR signaling pathway, which was mediated by the mutation of EGFR or KRAS, played an important role in the occurrence and development of NSCLC.

The sensitivity of tumor cells to TRAIL depended on the ratio of DR to DcR on the target cell membrane. High expression of DR contributed to the apoptosis of tumor cells, and high expression of DcR helped the cells escape TRAIL attack [16]. There was still much controversy over the complexity of TRAIL receptor system. But one thing in common was that no matter how the apoptotic signal was transduced in cells, TRAIL needed to combine with its receptors first, in order to induce cell apoptosis. Therefore, the expression level and function of TRAIL receptors on cell surface were particularly important for TRAIL-mediated apoptosis. Our research showed that in lung cancer tissues on the aspect of mRNA or protein level, the expression of DR5 was significantly higher than that in normal tumor-adjacent tissues, while the expression of DcR1 was significantly lower than that in tumor adjacent tissues, and the expression of these two were all relevant to the staging and differentiation of tumor. With higher NSCLC staging, DR5 mRNA and protein expression showed an increasing trend. The lower the degree of differentiation the higher the level of DR5 expression, suggesting that the overexpression of DR5 in NSCLC may be a vital cause for the promotion of tumor development and invasion. On the contrary, the mRNA and protein expression of DcR1 in NSCLC tissues decreased with the increasing stage of NSCLC, and the lower the degree of differentiation, the lower the expression level of DcR1, which indicated that due to DcR1 the relatively late stage and relatively low differentiated tumor cells showed decreased ability to escape apoptosis. This kind of tumor may be more sensitive to cytotoxic drugs. Further study showed that the mRNA and protein expression levels of DR5 and DcR1 in NSCLC tissue were not associated with the mutation status of EGFR and KRAS, which indicated that the combination of TRAIL and TRAILR was not affected by EGFR and KRAS signaling pathway.

In conclusion, our research suggested that among various clinicopathological factors smoking might have a bigger impact on the prognosis of patients with NSCLC. The mutative state of EGFR and KRAS gene was associated with the expression of AKT and AKT phosphorylation, and had nothing to do with the expression of TRAIL receptor. This phenomenon had some reference value to the comprehensive treatment strategy and the prognosis of NSCLC.

Supplementary information is available in the online version of the paper.

Acknowledgments: This study was sponsored by a research Grant from the Postdoctoral Research Fund (Grant No. LBHZ12159) provided by the Postdoctoral Management Office of Heilongjiang province, China, and a research Grant from Natural Science Foundation of Heilongjiang Province, China (Grant No. H201311) provided by the Committee of Natural Science Foundation of Heilongjiang Province. This study was also supported by a research Grant from the PhD Research Fund (Grant No. BS2012-16) provided by the Second Affiliated Hospital of Harbin Medical University. We thank to all participants who consented to take part in this trial.

\section{References}

[1] DENG LL, DENG HB, LU CL, GUO Y, WANG D et al. Mutations of EGFR or KRAS and expression of chemotherapy-related genes based on small biopsy samples in stage IIIB and IV inoperable non-small cell lung cancer. J Cancer Res Clin Oncol 2014; 140: 2097-2105. https://doi.org/10.1007/ $\underline{\text { s00432-014-1751-y }}$ 
[2] HUMTSOE JO, KRAMER RH. Differential epidermal growth factor receptor signaling regulates anchorage-independent growth by modulation of the PI3K/AKT pathway. Oncogene 2010; 29: 1214-1226. https://doi.org/10.1038/ onc.2009.419

[3] NAGARAJ NS, WASHINGTON MK, MERCHANT NB. Combined blockade of Src kinase and epidermal growth factor receptor with gemcitabine overcomes STAT3-mediated resistance of inhibition of pancreatic tumor growth. Clin Cancer Res 2011; 17: 483-493. https://doi.org/10.1158/1078-0432. CCR-10-1670

[4] ZHU X, JIANG H, LI J, XU J, FEI Z. Anticancer Effects of Paris Saponins by Apoptosis and PI3K/AKT Pathway in Gefitinib-Resistant Non-Small Cell Lung Cancer. Med Sci Monit 2016; 22: 1435-1441. https://doi.org/10.12659/ MSM.898558

[5] COLABUFO NA, CONTINO M, NISO M, BERARDI F, LEOPOLDO $\mathrm{M}$ et al. EGFR tyrosine kinase inhibitors and multidrug resistance: perspectives. Front Biosci (Landmark Ed) 2011; 16: 1811-1823. https://doi.org/10.2741/3823

[6] WANG T, GONG X, JIANG R, LI H, DU W et al. Ferulic acid inhibits proliferation and promotes apoptosis via blockage of PI3K/Akt pathway in osteosarcoma cell. Am J Transl Res 2016; 8: 968-980.

[7] KAMAL A, LAKSHMA NAYAK V, NAGESH N, VISHNUVARDHAN MV, SUBBA REDDY NV. Benzo[b]furan derivatives induces apoptosis by targeting the PI3K/Akt/ mTOR signaling pathway in human breast cancer cells. Bioorg Chem 2016; 66: 124-131. https://doi.org/10.1016/j. bioorg.2016.04.004

[8] BAO YX, ZHAO XD, DENG HB, LU CL, GUO Y et al. Schedule-dependent cytotoxicity of sunitinib and TRAIL in human non-small cell lung cancer cells with or without EGFR and KRAS mutations. Cell Oncol (Dordr) 2016; 39: 343-352. https://doi.org/10.1007/s13402-016-0278-4

[9] HE Q, XU Q, WU W, CHEN L, SUN W et al. Comparison of KRAS and PIK3CA gene status between primary tumors and paired metastases in colorectal cancer. Onco Targets Ther 2016; 9: 2329-2335. https://doi.org/10.2147/OTT.S97668

[10] RIQUELME E, BEHRENS C, LIN HY, SIMON G, PAPA DIMITRAKOPOULOU V et al. Modulation of EZH2 Expression by MEK-ERK or PI3K-AKT Signaling in Lung Cancer Is Dictated by Different KRAS Oncogene Mutations. Cancer Res 2016; 76: 675-685. https://doi.org/10.1158/0008-5472. CAN-15-1141

[11] LOPEZ-GOMEZ C, PINO-ANGELES A, ORPEZ-ZAFRA T, PINTO-MEDEL MJ, OLIVER-MARTOS B et al. Candidate gene study of TRAIL and TRAIL receptors: association with response to interferon beta therapy in multiple sclerosis patients. PLoS One 2013; 8: e62540. https://doi.org/10.1371/ journal.pone.0062540

[12] MENORET E, GOMEZ-BOUGIE P, GEFFROY-LUSEAU A, DANIELS S, MOREAU P et al. Mcl-1L cleavage is involved in TRAIL-R1 - and TRAIL-R2-mediated apoptosis induced by HGS-ETR1 and HGS-ETR2 human mAbs in myeloma cells. Blood 2006; 108: 1346-1352. https://doi.org/10.1182/ blood-2005-12-007971
[13] VAN NOESEL MM, VAN BEZOUW S, SALOMONS GS, VOUTE PA, PIETERS R et al. Tumor-specific down-regulation of the tumor necrosis factor-related apoptosis-inducing ligand decoy receptors DcR1 and DcR2 is associated with dense promoter hypermethylation. Cancer Res 2002; 62: 2157-2161.

[14] PARK EJ, MIN KJ, CHOI KS, KUBATKA P, KRUZLIAK P et al. Chloroquine enhances TRAIL-mediated apoptosis through up-regulation of DR5 by stabilization of mRNA and protein in cancer cells. Sci Rep 2016; 6: 22921. https://doi.org/10.1038/ $\underline{\operatorname{srep} 22921}$

[15] O'LEARY L, van DER SLOOT AM, REIS CR, DEEGAN S, RYAN AE et al. Decoy receptors block TRAIL sensitivity at a supracellular level: the role of stromal cells in controlling tumour TRAIL sensitivity. Oncogene 2016; 35: 1261-1270. https://doi.org/10.1038/onc.2015.180

[16] von PAWEL J, HARVEY JH, SPIGEL DR, DEDIU M, RECK $\mathrm{M}$ et al. Phase II trial of mapatumumab, a fully human agonist monoclonal antibody to tumor necrosis factor-related apoptosis-inducing ligand receptor 1 (TRAIL-R1), in combination with paclitaxel and carboplatin in patients with advanced nonsmall-cell lung cancer. Clin Lung Cancer 2014; 15: 188-196. https://doi.org/10.1016/j.cllc.2013.12.005

[17] KIM J, YUN M, KIM EO, JUNG DB, WON G et al. Decursin enhances TRAIL-induced apoptosis through oxidative stress mediated- endoplasmic reticulum stress signalling in nonsmall cell lung cancers. Br J Pharmacol 2016; 173: 1033-1044. https://doi.org/10.1111/bph.13408

[18] SHRADER M, PINO MS, LASHINGER L, BAR-ELI M, ADAM $L$ et al. Gefitinib reverses TRAIL resistance in human bladder cancer cell lines via inhibition of AKT-mediated X-linked inhibitor of apoptosis protein expression. Cancer Res 2007; 67: 1430-1435. https://doi.org/10.1158/0008-5472.CAN-06-1224

[19] MIRSADRAEE S, OSWAL D, ALIZADEH Y, CAULO A, van BEEK E JR. The 7th lung cancer TNM classification and staging system: Review of the changes and implications. World J Radio 2012; 1 4: 128-134.

[20] CHEN D, SONG Z, CHENG G. Clinical efficacy of first-generation EGFR-TKIs in patients with advanced non-small-cell lung cancerharboring EGFR exon 20 mutations. Onco Targets Ther 2016; 9: 4181-4186. https://doi.org/10.2147/OTT.S108242

[21] FIALA O, PESEK M, FINEK J, MINARIK M, BENESOVA L et al. Statins augment efficacy of EGFR-TKIs in patients with advanced-stage non-small cell lung cancer harbouring KRAS mutation. Tumour Biol 2015; 36: 5801-5805. https:// doi.org/10.1007/s13277-015-3249-x

[22] YANG Y, ZHANG B, LI R, LIU B, WANG L. EGFR-tyrosine kinase inhibitor treatment in a patient with advanced non-small cell lung cancer and concurrent exon 19 and 21 EGFR mutations: A case report and review of the literature. Oncol Lett 2016; 11: 3546-3550. https://doi.org/10.3892/ol.2016.4409

[23] KLUGHAMMER B, BRUGGER W, CAPPUZZO F, CIULEANU T, MOK T et al. Examining Treatment Outcomes with Erlotinib in Patients with Advanced Non-Small Cell Lung Cancer Whose Tumors Harbor Uncommon EGFR Mutations. J Thorac Oncol 2016; 11: 545-555. https://doi.org/10.1016/j. jtho.2015.12.107 
[24] GREIG MJ, NIESSEN S, WEINRICH SL, FENG JL, SHI M et al. Effects of Activating Mutations on EGFR Cellular Protein Turnover and Amino Acid Recycling Determined Using SILAC Mass Spectrometry. Int J Cell Biol 2015; 2015: 798936. https://doi.org/10.1155/2015/798936

[25] HSIA TC, TU CY, CHEN HJ. The impact of rescue or maintenance therapy with EGFR TKIs for Stage IIIb-IV non-squamous non-small-cell lung cancer patients requiring mechanical ventilation. BMC Anesthesiol 2014; 14: 55. https:// doi.org/10.1186/1471-2253-14-55

[26] PAN W, YANG Y, ZHU H, ZHANG Y, ZHOU R et al. KRAS mutation is a weak, but valid predictor for poor prognosis and treatment outcomes in NSCLC: A meta-analysis of 41 studies. Oncotarget 2016; 7: 8373-8388.

[27] LEE S, HEINRICH EL, LU J, LEE W, CHOI AH et al. Epidermal Growth Factor Receptor Signaling to the Mitogen Activated Protein Kinase Pathway Bypasses Ras in Pancreatic Cancer Cells. Pancreas 2016; 45: 286-292. https://doi.org/10.1097/ MPA.0000000000000379

[28] SMOLENSKY D, RATHORE K, CEKANOVA M. Phosphatidylinositol-3-kinase inhibitor induces chemosensitivity to a novel derivative of doxorubicin, AD198 chemotherapy in human bladder cancer cells in vitro. BMC Cancer 2015; 15 : 927. https://doi.org/10.1186/s12885-015-1930-5 
Supplementary Table 1 The sequences of ASPE primers used for the 56plex

\begin{tabular}{|c|c|c|}
\hline Genes & Type & Universal tage -Primer, 5' $\rightarrow 3^{\prime}$ \\
\hline EGFR & WT & ATACTTCATTCATTCATCAATTCA CCGAACGCACCGGAGC \\
\hline \multirow[t]{3}{*}{ Exon18 } & G719A & ATACAATCTAACTTCACTATTACA GTGCCGAACGCACCGGAGG \\
\hline & G719C & CTTTAATCTACACTTTCTAACAAT CCGAACGCACCGGAGCA \\
\hline & G719S & ATACTACATCATAATCAAACATCA CCGAACGCACCGGAGCT \\
\hline \multirow[t]{2}{*}{ EGFR } & WT & СТTCTCATTAАСТTАСТTСАТААТ \\
\hline & & CTATCAAGGAATTAAGAGAAGC \\
\hline \multirow[t]{22}{*}{ Exon19 } & E746-A750 (1) & TCAATTACTTCACTTTAATCCTTT AАTTCCCGTCGCTATCAAAAC \\
\hline & E746-A750 (2) & CTTTTCATCAATAATCTTACCTTT TTCCCGTCGCTATCAAGACA \\
\hline & L747-E749 ins P & AAACAAACTTCACATCTCAATAAT CGTCGCTATCAAGGAACCAA \\
\hline & L747-A750 ins P & TCATTTCAATCAATCATCAACAAT CGTCGCTATCAAGGAACCAT \\
\hline & L747-T751 & TCAATCATCTTTATACTTCACAAT CGTCGCTATCAAGGAATCT \\
\hline & L747-T751 ins A & TTACTCAAAATCTACACTTTTTCA CCCGTCGCTATCAAGGCAT \\
\hline & L747-S752 & СTTTTTCAATCACTTTCAATTCAT CCGTCGCTATCAAGGAACAT \\
\hline & L747-S752 ins V & CAATATCATCATCTTTATCATTAC CCCGTCGCTATCAAGGTTC \\
\hline & L747-S752 ins D & AATCTACAAATCCAATAATCTCAT CCGTCGCTATCAAGGATCC \\
\hline & L747-S752 ins Q & ATCAAATCTCATCAATTCAACAAT CGTCGCTATCAAGGAACAG \\
\hline & L747-S752 ins S & TTCATAACTACAATACATCATCAT CGTCGCTATCAAGGAATCG \\
\hline & E749-S752 ins D & AAАCTAACATCAATACTTACATCA \\
\hline & & CTATCAAGGAATTAAGAGATCC \\
\hline & E746-T751 ins $\mathrm{T}$ & TCAAAATCTCAAATACTCAAATCA TCCCGTCGCTATCAAGACC \\
\hline & E746-P753 ins VS & CTACTAATTCATTAACATTACTAC CCCGTCGCTATCAAGGTCT \\
\hline & E746-T751 ins Y & CTACAAАCAAАCAAАCATTATCAA \\
\hline & & CCGTCGCTATCAAGGAACAA \\
\hline & E746-T751 ins A & TAACATTACAACTATACTATCTAC CCCGTCGCTATCAAGGCTT \\
\hline & E746-T750 ins AP & TATATACACTTCTCAATAACTAAC TCGCTATCAAGGCCCCAAC \\
\hline & E747-T751 ins V & CTTTTCATCTTTTCATCTTTCAAT CGTCGCTATCAAGGTATCT \\
\hline & L747-S752 ins E & CTTTAATCCTTTATCACTTTATCA CGTCGCTATCAAGGAACCG \\
\hline & R748-T751 ins LS & TTACCTTTATACCTTTCTTTTTAC CGCTATCAAGCTATCAAGCC \\
\hline EGFR & WT (1) & TCAATTACCTTTTCAATACAATAC CACCGTGCAGCTCATCAC \\
\hline Exon20 & WT (2) & TACACTTTCTTTCTTTCTTTCTTT AAGCCTACGTGATGGCCAG \\
\hline & T790M & TCATTTACCAATCTTTCTTTATAC CCACCGTGCAGCTCATCAT \\
\hline
\end{tabular}


S768I

V769_D770 ins ASV

D770_N771 ins G

H773_V774 ins H

EGFR WT (1)

Exon21 WT (2)

L858R (1)

L858R (2)

L861Q

KRAS WT (1)

Exon2 WT (2)

G12A

G12C

G12D

G12R

G12S

G12V

G13A

G13C

G13D

G13R

G13S

G13V

KRAS WT

Exon3 Q61H

Q61K

Q61L
AATCTAACAAACTCATCTAAATAC AAGCCTACGTGATGGCCAT

TACAAATCATCAATCACTTTAATC GATGGCCAGCGCCAGCGTG

TACATACACTAATAACATACTCAT GTGATGGCCAGCGTGGGT

CAATAAACTATACTTCTTCACTAA CGTGGACAACCCCCACCA

TAATTATACATCTCATCTTCTACA CAAGATCACAGATTTTGGGCT

CTACTATACATCTTACTATACTTT GATTTTGGGCTGGCCAAACT

CTTTTCAATTACTTCAAATCTTCA AAGATCACAGATTTTGGGCG

CAATATACCAATATCATCATTTAC AGATCACAGATTTTGGGCGT

CTACATATTCAAATTACTACTTAC GATTTTGGGCTGGCCAAACA

AATCAATCTTCATTCAAATCATCA TTGTGGTAGTTGGAGCTGGT

AATCTTACCAATTCATAATCTTCA GTAGTTGGAGCTGGTGGC

CTTTTCAAATCAATACTCAACTTT TGGTAGTTGGAGCTGCT

TTCAATCATTCAAATCTCAACTTT TTGTGGTAGTTGGAGCTT

CTTTCTACATTATTCACAACATTA TTGTGGTAGTTGGAGCTGAT

TCATTTACTCAACAATTACAAATC TGTGGTAGTTGGAGCTCG

TCATAATCTCAACAATCTTTCTTT CTTGTGGTAGTTGGAGCTA

CAATTTACTCATATACATCACTTT TTGTGGTAGTTGGAGCTGTT

TACACATCTTACAAACTAATTTCA GGTAGTTGGAGCTGGTGC

TCAATCATAATCTCATAATCCAAT TGGTAGTTGGAGCTGGTTG

CAATTAACTACATACAATACATAC TGGTAGTTGGAGCTGGTGA

CTACTTCATATACTTTATACTACA GGTAGTTGGAGCTGGTCG

CTTTCAATTACAATACTCATTACA TGGTAGTTGGAGCTGGTAG ATACCAATAATCCAATTCATATCA TGGTAGTTGGAGCTGGTGT AATCATACCTTTCAATCTTTTACA ATTGCACTGTACTCCTCTTG TTCACTTTTCAATCAACTTTAATC CATTGCACTGTACTCCTCA TTACTTCACTTTCTATTTACAATC CATTGCACTGTACTCCTCTTT AATCTTACTACAAATCCTTTCTTT TCATTGCACTGTACTCCTCTA 
Supplementary Table 2 PCR primers used for the 56plex

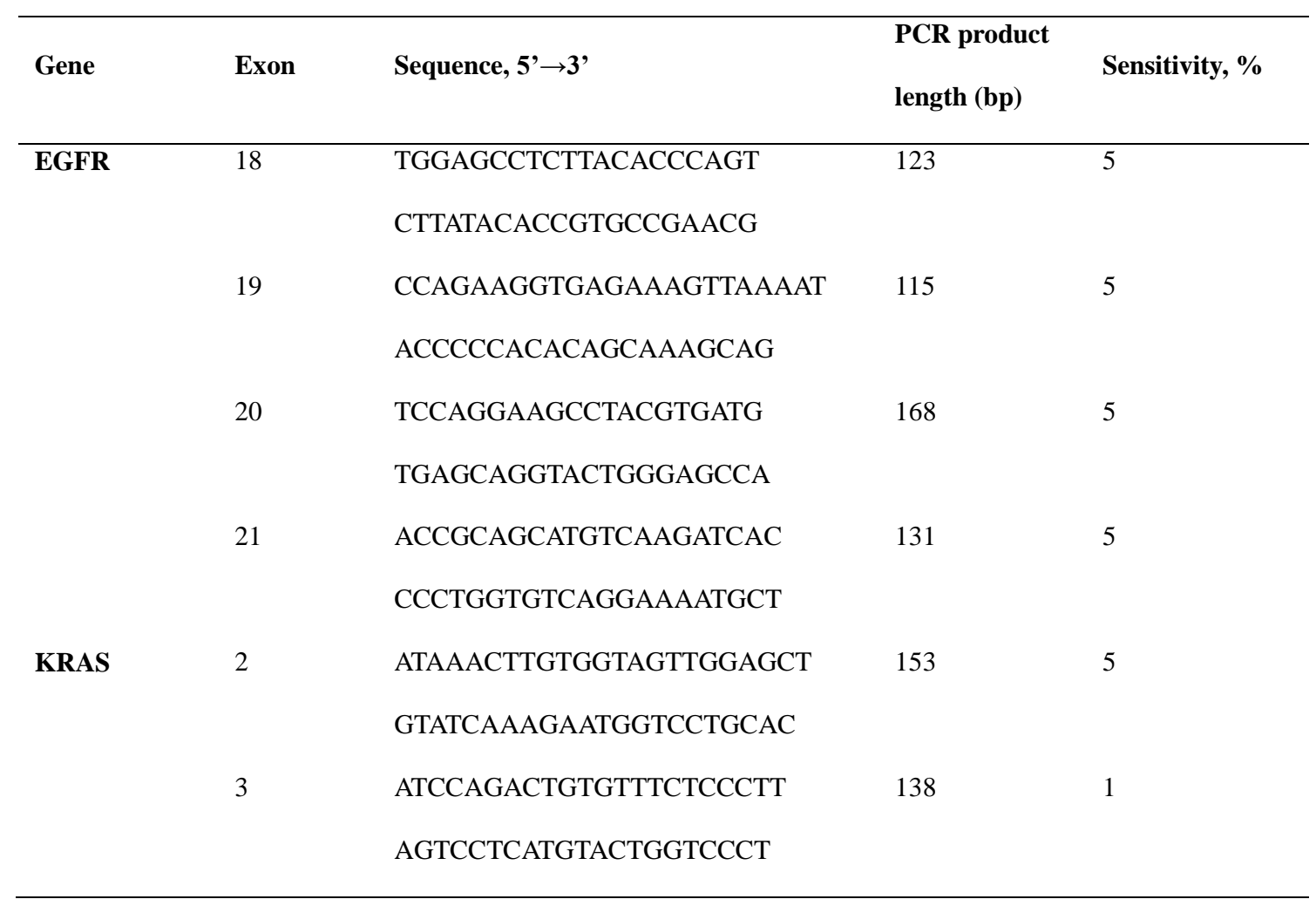

